\title{
O Direito Sanitário na Modernidade - Prenúncios da Autonomia de um Novo Ramo Jurídico
}

\author{
THE SANITARY RIGHT IN MODERNITY - PREMESSENGERS OF \\ THE AUTONOMY OF A NEW LEGAL BRANCH
}

Luiz Henrique Sormani Barbugiani(*)

\section{RESUMO}

A autonomia de uma disciplina juridica depreende-se da análise de um conjunto de elementos significativos que justificam o estudo de uma matéria em suas pecualiaridades conceituais, principiológicas e metodológicas. Alguns elementos são meramente indiciários, outros essenciais para o reconhecimento de uma autonomia relativa, uma vez que apenas o Direito como ciência pode ser considerado absolutamente autônomo, contudo todos são de importância crucial para se estabelecer os prenúncios do despontar de um novo ramo jurídico.

\section{Descritores}

Direito sanitário; Princípios jurídicos; Métodos de pesquisa; Ensino jurídico.

\section{ABSTRACT}

The autonomy of one disciplines legal is inferred of the analysis of a set of significant elements that justifcam the study of a substance in its conceptual, principiológicas and metodológicas peculiarities. Some elements are mere indiciários, other essentials for the recognition of a

(*)Graduado em Direito pela Universidade Estadual Paulista - "Júlio de Mesquita Filho" - UNESP, com habilitação especial em Direito Empresarial, especialista em Direito Sanitário pela Universidade de São Paulo - USP/CEPEDISA, especialista em Saúde Pública pela Universidade de Ribeirão Preto - UNAERP, ex-Procurador do Municipio de Araraquara, exerce atualmente o cargo de Advogado concursado do Municipio de Mogi das Cruzes. 
relative autonomy, a time that only the Right as science can be considered absolutely independent, however all are of crucial importance to establish or premessengers of blunting of a new legal branch.

\section{Keywords}

Sanitary right; Legal principles; Methods of Research; Legal education.

\section{INTRODUÇÃO}

Uma questão que tem gerado diversos questionamentos e discussões, seja no mundo juridico, seja no âmbito sanitário refere-se à autonomia e aplicabilidade do denominado Direito Sanitário.

Os debates tem suscitado posicionamentos antagônicos e contrários, dependendo, geralmente, dos interlocutores envolvidos, bem como dos profissionais que se utilizam desse novo ramo juridico. Alguns entendem que o Direito Sanitário é uma expressão destituida de interesse, afirmando que é mera atuação prática do Direito Administrativo, outros chegam a defender a total e absoluta independência do Direito Sanitário em relação aos conceitos tradicionais da ciência juridica.

Ante os posicionamentos acima descritos, levando em conta que no direito nada é absoluto, principalmente, por compreender uma ciência humana, englobada no "mundo do dever ser", com uma dose exacerbada de subjetivismo e interpretações e, portanto, diversa das ciências da natureza, caracterizadas por verdades comprovadas por experimentos técnicos, como por exemplo, a física, química, matemática, entre outras em que o subjetivismo inexiste ou é quase nulo, pertencentes ao que se convencionou denominar "mundo do ser", o posicionamento mais salutar é o mediador ou melhor dizendo, nem a primeira corrente, nem a segunda estão inteiramente corretas, pois são extremadas, sem qualquer fundamentação sólida.

Utiliza-se propositadamente, neste artigo, da expressão "novo ramo jurídico" quando se trata do Direito Sanitário, visto que com o surgimento da concepção moderna de Direito deve-se entender que a ciência juridica é una ou melhor o Direito como ciência é absolutamente autônomo, em relação às demais ciências conhecidas, entretanto, não impede a constatação que mesmo com a presença dessa unidade, ao longo dos anos, foram surgindo especializações do Direito, conhecidas pelos doutrinadores como ramos autônomos.

O termo ramo foi adaptado, simbolizando os inúmeros ramos de uma árvore que, por sua vez, estão ligados ao tronco principal, que representa a ciência denominada Direito. 
Apesar da unidade da ciência, verificou-se o surgimento de braços especializados, hoje tradicionalmente reconhecidos, tais como, o Direito Civil, o Direito Comercial, o Direito Penal, o Direito do Trabalho, o Direito Constitucional, o Direito Administrativo, o Direito Processual, o Direito Tributário, Direito Internacional entre tantos outros que permeiam o mundo jurídico.

O autor, Edis Milaré(1), ressalta a autonomia relativa dos ramos do Direito, tendo em vista, o entrelaçamento das diversas disciplinas juridicas entre si, sendo providencial, nesse momento, a transcrição da explanação do mencionado doutrinador:

... por mais que se considerem autônomos certos ramos do Direito, haverá sempre entre eles alguma intercomunicação, algum traço comum e até mesmo alguma dependência em certos ângulos ou assuntos.

A especialização ou aprimoramento do direito, é um fato social e, portanto, apreciável também por outras ciências como a sociologia, a psicologia, a filosofia, apenas para citar três exemplos.

Como fato social, explica-se a especialização dos ramos juridicos, na necessidade perene da sociedade adequar-se às normas jurídicas, às modificações constantes decorrentes das inovações tecnológicas, culturais, históricas, políticas, econômicas, étnicas e sociais que refletem os anseios da coletividade e influenciam na elaboração das leis pelo Poder Legislativo.

Como definir se um ramo jurídico adquiriu autonomia frente a outro ramo?

A resposta é simples, existem parâmetros para se alcançar a solução do problema.

Os elementos que devem permear o ramo jurídico para autorizar, segundo outros indiciar ou, ainda, justificar a designação de ramo autônomo, são variados, sendo objeto de análise nas linhas abaixo.

O Direito Sanitário, como reflexo da evolução social e constitucional embasadora do desenvolvimento contínuo da ciência juridica, tem uma disciplina irmã no Direito Ambiental.

A diferença primordial entre os dois novos ramos da ciência jurídica, encontra-se, no enfoque dado ao meio ambiente e na existência de um maior número de obras publicadas que tratam do jovem Direito Ambiental, questionamentos estes que não serão analisados nesse artigo, uma vez que merecem um trabalho especifico devido a sua extensão e complexidade.

(1) MILARÉ, Edis. Direito do ambiente, 2 ed. São Paulo: Ed. Revista dos Tribunais, 2001, p. 128. 
Assim, diante das semelhanças será utilizado o posicionamento de doutrinadores do Direito Ambiental, para auxiliar na compreensão do Direito Sanitário como disciplina autônoma.

Apesar de diferirem na conceituação, muitas das observações aplicáveis ao Direito Ambiental são aproveitadas pelo Direito Sanitário, uma vez que derivam de mandamentos constitucionais e não de normas infraconstitucionais.

O renomado doutrinador, Paulo de Bessa Antunes(2), esclarece a posição do Direito Ambiental em relação aos demais ramos da ciência jurídica, conclusões que se transportam sem ressalvas para o Direito Sanitário:

O Direito Ambiental não se encontra situado em "paralelo" a outros "ramos" do Direito. O Direito Ambiental é um direito de coordenação entre estes diversos "ramos". E, nesta condição, é um Direito que impõe aos demais setores do universo jurídico o respeito às normas que o formam, pois o seu fundamento de validade é emanado diretamente da Norma Constitucional...

Vislumbra-se, logo, que tanto o Direito Sanitário como o Ambiental apresentam em seus dispositivos legais, exclusivamente, normas cogentes, também denominadas de ordem pública.

A diferenciação entre as normas dispositivas e coativas foi muito bem especificada pelo ilustre doutrinador Vicente Ráo(3):

A maior ou menor força obrigatória das normas de direito objetivo produz mais uma distinção entre direito absoluto (ou coativo, ou imperativo, jus cogens) e direito dispositivo (ou permissivo, supletivo, subsidiário, indicativo).

O primeiro possui uma obrigatoriedade incondicionada, insuscetivel de alteração, ou inaplicação, pela vontade dos que Ihes estão subordinados; o segundo somente se torna obrigatório quando as partes não disciplinam suas relações por modo diverso do por ele previsto.

$\dot{E}$ absoluto todo o direito público e a parte do direito privado considerada como de ordem pública. Fora desses casos, o direito objetivo sempre assegura a eficácia juridica dos atos de vontade, só intervindo, na sua falta, para integrá-la, ou supri-la."

(2) ANTUNES, Paulo de Bessa. Direito ambiental, 5 ed. Rio de Janeiro: Lúmen Júris, 2001, p. 24-25.

(3) RÁO, Vicente. O direito e a vida dos direitos, 4 ed. São Paulo: Ed. Revista dos Tribunais, 1997, vol. 1, p. 212. 
Percebe-se, por conseguinte, que o Direito Sanitário, faz parte do Direito Público, divisão do Direito, classicamente, aplicada, desde sua definição por Ulpiano ao dividir o Direito em Público e Privado.

Não poderia ser diferente, já que os bens jurídicos protegidos pelas normas de Direito Sanitário, ou seja, a vida e saúde humana, não podem ser preteridos, devido a isso, suas normas não são afastadas pela vontade do particular, constituindo-se em verdadeiros dispositivos inderrogáveis.

O autor ${ }^{(4)}$ constata, também, a tendência de publicização do Direito moderno, vislumbrando que as normas de ordem pública derivam de razões sociais e das relações contempladas:

Não é possivel indicar a priori, por via de definição ou conceito geral, todas as normas de ordem pública. É da natureza de cada disposição, da natureza das relações contempladas e das razões sociais determinantes de cada norma, que esse caráter resulta.

Certo é, contudo, que, no direito moderno, o legislador tende a imprimir esse maior grau de eficácia à disciplina de um número sempre crescente de relações, que, outrora, eram regidas pelas normas meramente dispositivas do direito privado.

A publicização do Direito tem como origem, o descaso humano para com o resguardo dos bens utilizados por todos, como, ar, água, terra, lavoura, pecuária etc.

O Direito moderno, sendo o Direito Sanitário, um exemplo, visa resguardar todos os indivíduos, estes considerados cidadãos tutelados pelas normas constitucionais.

Paulo de Bessa Antunes(5) captou magistralmente esse fenômeno:

"Os direitos que vêm surgindo recentemente, sobretudo à partir da década de 60 do século $X X$, são essencialmente direitos de cidadania, ou seja, direitos que se formam em decorrência de uma crise de legitimidade da ordem tradicional. O movimento de cidadãos conquista espaços politicos que se materializam em leis de conteúdo, função e perspectivas bastante diversos dos conhecidos pela ordem jurídica tradicional..."

O legislador atentou-se ao fato de que a saúde humana, não poderia ser regulada, exclusivamente, pela vontade particular, uma vez que tais bens envolvem toda a coletividade, não podendo ser manipulados pelos detentores do poder econômico.

(4) Id. Ibid., p. 213.

(5) ANTUNES, Paulo de Bessa. Op. cit., p. 24. 
A proteção constitucional aos direitos fundamentais do ser humano, entre os quais a saúde, se imiscui em todos os outros ramos do Direito, tamanha a sua importância, visto que no conflito de bens juridicos tutelados, preponderam àqueles de maior significado.

O mesmo doutrinador ${ }^{(6)}$, analisando a relação do Direito Ambiental com os demais ramos da ciência jurídica, capta a relação transversal existente, com a supremacia daquele, averiguações transportadas também para o Direito Sanitário:

... "Sabemos, contudo, que não se pode conceber o Direito Ambiental dentro dos quadros do Direito tradicional. A relação do Direito Ambiental com os demais ramos do Direito é uma relação transversal, isto é, as normas ambientais tendem a se incrustrar em cada uma das demais normas juridicas, obrigando a que se leve em conta a proteção ambiental em cada um dos demais "ramos" do Direito. O Direito Ambiental penetra em todos os demais ramos da Ciência Jurídica..."

O Direito Ambiental, como direito humano fundamental, não pode ficar subordinado às regras do direito do proprietário ou do Direito do patrão, assim como não pode ficar subordinado às regras do Direito do Estado contra os direitos da cidadania; ao contrário, são aqueles direitos que devem se subordinar e se transformar em razão de necessidades prementes da humanidade que se refletem juridicamente na categoria dos direitos humanos fundamentais.

O Direito Sanitário, configura-se, assim como o Direito Ambiental, num reflexo da tendência mundial do Direito Moderno.

\section{INDÍCIOS DA AUTONOMIA DO DIREITO SANITÁRIO}

A autonomia de um ramo da ciência jurídica, como se observou, nas linhas acima, não é absoluto, pois há um entrelaçamento entre os diversos ramos.

Devido a isso, a autonomia é considerada meramente relativa, caracterizada pela interdependência das inúmeras disciplinas juridicas, sem, contudo, desconsiderar a existência de conceitos, principios e institutos próprios.

Esse aspecto da autonomia foi muito bem salientado por Paulo de Bessa Antunes ${ }^{(7)}$ :

... o conceito de autonomia dos diversos ramos do direito é bastante discutido e discutivel. Sabemos que o conceito de autonomia dos

(6) Id. Ibid., p. 24-25.

(7) Id. Ibid., p. 24. 
diversos ramos do Direito implica a existência de setores estanques no interior da ordem jurídica que, apenas e tão somente, mantêm algumas relações formais entre si. Ora, na realidade, tal concepção é falha, pois os conceitos fundamentais do Direito tradicional são válidos em qualquer dos diferentes "ramos" do Direito. O conceito de Sujeito de Direito é valido tanto para o Direito Penal quanto para o Direito Tributário ou o Direito Civil. Acresce, ademais, que a idéia de ramos autônomos do Direito está vinculada à concepção da existência de um certo "paralelismo" entre os diversos ramos da Ciência do Direito.Assim, existe um Direito Civil que é paralelo ao Direito Administrativo, que, por sua vez, é paralelo ao Direito Penal e assim sucessivamente.

O bom senso preconiza que não se deve valer para estabelecer a autonomia de uma disciplina juridica, do modismo, do imediatismo, da vontade de inovar simplesmente por inovar, mas sim da sedimentação de elementos suficientes a justificar o surgimento de um novo ramo.

Carlos Maximiliano(8), atenta para esse problema, determinando que devem ser tomadas cautelas quando o operador do Direito se depara com uma inovação ou novidade:

Na verdade, seria perigoso seguir logo o primeiro livro que se abrisse; pior ainda o obedecer às cegas ao espírito de inovação, preferir tudo quanto é ou parece novidade. Sobretudo o juiz deve aplicar a boa doutrina, porém depois de vencedora pelo menos nas cátedras escolares e entre tratadistas; a solução teórica definitiva, que o maior número é obrigado a conhecer para se orientar na pratica e evitar os litígios. Adotar logo a primeira novidade é estabelecer a surpresa nos julgamentos, e revelar injusto desdém pelas vantagens decorrentes da certeza do Direito.

O Direito Sanitário não é uma inovação ou novidade sem elementos que propiciem sua caracterização como ramo autônomo do Direito, muito pelo contrário, configura-se num Direito Especial.

O tratamento jurídico especial dado pelo Direito Sanitário às questões que envolvem a saúde pública, decorre das próprias relações sociais especificas que regula.

Paulo Dourado de Gusmão(9), coaduna do mesmo entendimento, ao analisar o conceito de Direito Especial, em sua obra Introdução ao Estudo do Direito:

(8) MAXIMILIANO, Carlos. Hermenêutica e aplicação do direito, 19 ed. Rio de Janeiro: Forense, 2002, p. 160.

(9) GUSMÃO, Paulo Dourado de. Introdução ao estudo do direito, 8 ed. Rio de Janeiro: Forense, 1978 , p. 116. 
Em alguns casos, por questões históricas ou pela natureza da própria relação social, é útil e necessário que certas relações tenham tratamento juridico especial.

De modo geral, o direito especial pode ser tido como exceção ao geral, porém não deve ser considerado como direito excepcional, porque este é ditado para relações jurídicas que, por natureza, se enquadram na norma geral, mas que, por questão de oportunidade ou necessidade históricas, têm tratamento juridico diferente do gênero. Já as relações jurídicas regidas pelo direito especial só têm alguns pontos de semelhança com as disciplinadas com o direito geral, porém, ao contrário destas, têm aspectos que as tornam diversas das comuns e que exigem tratamento especial. Exemplo tipico de direito geral é o direito civil, têm aspectos especiais, que exigem tratamento especial ( $\$ 115)$. Outro exemplo de direito especial: Código do Ministério Público (lei especial), enquanto o Estatuto dos Funcionários Públicos (lei geral) é exemplo de direito geral.

O Direito Especial com o passar dos anos e a evolução natural das normas juridicas pode se transformar em ramo ou sub-ramo do Direito, como bem observa Vicente Ráo(10):

Muitas vezes, também, o direito especial, porventura revelado, em sua origem, por leis esparsas, vai, aos poucos, se constituindo em um sistema orgânico de normas, subordinando-se a princípios próprios; $e$, neste caso adquirindo caráter permanente, ora constitui ramo ou sub-ramo do direito, como já dissemos (por exemplo: o direito comercial, o direito fiscal, o direito do trabalho etc.), ora constitui, apenas, um corpo de leis, ou disposições legais, aplicável a certas relações, ou a certas pessoas, como, ainda por exemplo, a legislação estatutária dos funcionários públicos, a que organiza e disciplina o exercício e as condições éticas e econômicas de certas profissões (advogados, médicos, jornalistas etc.), ou de certas relações (assim a relativa à proteção do fundo de comércio nas locações de prédios comerciais e industriais etc.)

Os critérios prenunciadores da autonomia podem ser essenciais para a constatação ou meramente indiciários, sendo analisados um a um nas linhas abaixo.

\section{AUTONOMIA LEGISLATIVA}

A independência legislativa da matéria esta associada, segundo parte da doutrina, à instituição de um código que como lei nova e única regularia a disciplina especifica.

(10) RÁO, Vicente. Op. cit., p. 210. 
Esse elemento não é essencial, pois o Direito Agrário reconhecido, expressamente, como autônomo pelo art. 22, I da CF, não tem compilação em código. O diploma legal no âmbito agrário é o Estatuto da Terra que não é considerado um código na essência da palavra.

Da mesma maneira que o Direito Agrário, o Direito do Trabalho se consubstancia numa mera consolidação legal conhecida como CLT, não configurando uma lei nova mas sim um conjunto de normas reunidas, enquanto $o$ administrativo apresenta apenas leis esparsas.

Confirmando a relevância da questão sanitária, existem variados diplomas legais que direta ou indiretamente regulam os fatos sociais relacionados com a área da saúde.

A Constituição Federal de 1988 apresenta uma seção específica para a saúde englobada dentro do Capítulo da Seguridade Social. A Constituição Paulista segue o exemplo da Carta Magna, na disposição do tema.

O Código Penal apresenta um capítulo específico tratando dos crimes contra a saúde pública e em âmbito federal foi editada a lei orgânica da saúde, Lei n. 8.080/90.

O Estado de São Paulo foi um dos pioneiros em estabelecer um Código de Saúde e um Código Sanitário Estadual disciplinando as atividades de interesse à saúde.

Numa rápida análise da legislação sanitária, que engloba não só a lei em sentido estrito, mas também, qualquer ato normativo editado pelo Poder Executivo constata-se a presença na Administração Pública, em qualquer esfera de governo, de inúmeros Decretos, Portarias e Resoluções das Secretarias Estaduais de Saúde, dos Centros de Vigilância Sanitária e Epidemiológica, da Funasa, do Ministério da Saúde e de agências como a ANS e ANVISA, sendo, portanto, incontestável a autonomia legislativa.

\section{AUTONOMIA DOUTRINÁRIA}

A constatação desse elemento percebe-se através da publicação de inúmeros artigos e livros na área do Direito Sanitário. Esse artigo é um típico exemplo da presença desse esse elemento indiciário.

Dentro da emergente produção doutrinária pode-se destacar os diversos artigos e obras publicadas pela professora Dra. Sueli Gandolfi Dallari, eminente profissional e fabulosa congressista internacionalmente reconhecida na área do Direito Sanitário.

\section{AUTONOMIA JUDICIAL}

A instrumentalização do Poder Judiciário é necessária para viabilizar a aplicação do Direito Sanitário. 
No pais existem varas trabalhistas especializadas em aplicar o Direito do Trabalho, varas federais com competência estabelecida na Constituição Federal compondo o Poder Judiciário da União e varas estaduais da justiça comum representando o Poder Judiciário em âmbito estadual, estas últimas em comarcas de grande contingente populacional e, conseqüentemente, de processos ajuizados, especializaram-se em determinadas áreas como as varas da Fazenda Pública, de Direito de Família, Direito Falimentar e algumas vozes abalizadas já exigem a criação urgente de varas agrárias e ambientais para julgar as questões fundiárias e de cunho ambiental.

Não é um fator essencial para autorizar a existência de um ramo autônomo, pois, por exemplo, o Direito Administrativo e o Direito Ambiental que têm reconhecida sua autonomia não possuem ainda varas especializadas em sua aplicação.

A jurisprudência, assim como a doutrina, são consideradas fontes formais indiretas do Direito, asseverando a importância do Direito Sanitário quando se analisam questões relacionadas à saúde.

As fontes diretas são representadas pela lei em sentido estrito e demais normas, englobando ainda os principios, a analogia e os costumes.

A diferença primordial entre as fontes diretas e indiretas consiste na aplicabilidade das primeiras solucionando o caso concreto de maneira imediata, seja por referir-se a meios de integração do ordenamento juridico, seja por decorrerem da própria lei.

As fontes indiretas, por sua vez, são consideradas interpretações efetuadas pela doutrina e jurisprudência da legislação em vigor e aplicáveis de maneira mediata ao caso concreto.

Assim, a existência de entendimento jurisprudencial sobre questões que envolvam o Direito Sanitário confirma a presença de indícios da autonomia desse ramo jurídico.

\section{AUTONOMIA ACADÊMICA}

A presença desse elemento verifica-se com o crescente interesse nesta disciplina que começa a ser ministrada em algumas universidades, quer na graduação, quer na pós-graduação em instituições conceituadas como a Universidade de São Paulo, a Universidade de Brasilia e a Fiocruz no Rio de Janeiro.

Significado relevante tem esse elemento, pois reflete os anseios da sociedade que busca se atualizar quanto à matéria e exige cursos, palestras, congressos e disciplinas ministradas nas universidades para proporcionar a capacitação de profissionais da área. 
Um exemplo da relevância desse elemento indiciário encontra-se na permanência da disciplina Direito Comercial em todas as faculdades de Direito conceituadas, mesmo após as normas comerciais passarem a se inserir dentro do novo Código Civil, uma vez que a localização tópica das normas em outros diplomas legais não desconstitui a sua autonomia.

\section{AUTONOMIA CIENTÍFICA}

O elemento primordial e essencial da definição da autonomia de um ramo juridico é perceptivel quando uma disciplina apresenta conceitos, definições, institutos e métodos de pesquisa próprios, bem como principios que garantam a sustentação e organicidade da matéria.

Nesse mesmo sentido Edis Milaré(11) se posicionou ao constatar a autonomia do Direito Ambiental:

Pode-se afirmar, sem medo de errar. Que, no Brasil, o Direito do Ambiente é na realidade um "Direito adulto". Conta ele com principios próprios, com assento constitucional e com um regramento infraconstitucional complexo e moderno. Além disso, tem a seu dispor toda uma estrutura administrativa especializada e instrumentos eficazes de implementação.

Conceitos e definições são considerados sinônimos por alguns doutrinadores, contudo, o mais correto é entender ser diverso o seu significado.

Definição é um termo que traz consigo um sentido absoluto ou para ser mais específico, é uma formula em vernáculo da língua portuguesa que exprime de maneira exata e sem interferências subjetivas de interpretação uma realidade já pacificada e comprovada tecnicamente.Um exemplo está na palavra "água", que imediatamente pode ser definida como $\mathrm{H}_{2} \mathrm{O}$, ou seja duas partes de hidrogênio para uma de oxigênio, definição comprovada pela química e sem qualquer contestação.

Conceito, ao contrário do termo definição, denota uma certa carga de subjetivismo, pois não é estático, mas sim dinâmico modificando-se em certos aspectos, relacionados invariavelmente com a observação do individuo que emite o senso de valor sobre determinada situação. Um exemplo seria a palavra "amor", que entende-se de maneiras diferentes, variações decorrentes da diversidade cultural, étnica, social, econômica, política, religiosa, dentre tantos outros fatores influenciadores da percepção daquele que se utiliza do termo.

(11) MILARÉ, Edis. Op. cit., p. 126. 
Nesse contexto pode-se esclarecer que enquanto o conceito de "amor" para uma pessoa pode ser o provimento das necessidades materiais de seus entes queridos, para outros estaria no convivio constante entre os membros de uma familia. Assim, percebe-se a relatividade e a dose de subjetivismo que interfere na conceituação de determinados termos.

Todavia, essa diferenciação apesar de ser relevante não apresenta demasiada importância prática, uma vez que mesmo a definição de um termo poderá ser com o passar dos anos aprimorada ou modificada frente as inovações tecnológicas e as cotidianas descobertas e redescobertas da ciência que nesse sentido invalidariam o caráter estático e absoluto daquilo que se convencionou denominar definição.

A título de exemplo pode-se citar como conceitos próprios, os termos "saúde" entendida segundo parâmetros da Organização Mundial de Saúde; "Direito Sanitário" envolvendo o conjunto de normas, princípios e métodos de pesquisa desse novo ramo jurídico; "resolução da diretoria colegiada" consistente em normas de cunho sanitário editadas pela Agência Nacional de Vigilância Sanitária, entre outros.

Os métodos de pesquisa especificos configuram um conjunto de meios dispostos com o intuito de alcançar um fim, objetivando atingir um conhecimento científico dentro de uma área predeterminada ou comunicálo a outras pessoas. Eles variam conforme o ângulo adotado pelo pesquisador para implementar a observação dos fatos submetidos à análise e possibilitar uma conclusão.

Toda ciência tem métodos peculiares adequados às suas necessidades, da mesma forma que os sub-ramos dela se especializam em critérios metodológicos para atender as caracteristicas incomuns da matéria em relação ao todo, sendo praticamente impossivel enumerá-los, restringindo aquilo que é irrestrito no campo da pesquisa.

Os institutos próprios podem ser concebidos de duas maneiras distintas, a primeira como órgãos que interferem ou viabilizam a aplicação do ramo jurídico autônomo; a segunda como elementos que diferenciam o Direito Sanitário das demais especializações da ciência juridica.

Quanto ao primeiro aspecto, encontra-se nas estruturas da Administração Pública variados órgãos e entidades que instrumentalizam a aplicação do Direito Sanitário, no âmbito municipal a Secretaria Municipal de Saúde através dos Departamentos de Vigilância em Saúde, atuando em conjunto com a Secretaria Municipal de Assuntos Jurídicos; no âmbito do Estado de São Paulo, a Secretaria do Estado da Saúde, que por sua vez atua em conjunto com outros órgãos a ela vinculados como o Centro de Vigilância Sanitária e Epidemiológica atualmente na estrutura coordenadora de seus grupos técnicos das Direções Regionais de Saúde, que posteriormente segundo projeto de lei passarão a constituir uma nova entidade nos moldes da ANVISA, atuando em conjunto com a Procurado- 
ria Geral do Estado; no âmbito federal o Ministério da Saúde que também utiliza-se de entidades como a Agência Nacional de Vigilância Sanitária, Fundação Nacional de Saúde e Agência Nacional de Saúde Suplementar na aplicação do Direito Sanitário, atuando em conjunto com os procuradores federais.

No sentido de institutos próprios como elementos que diferenciam o Direito Sanitário dos demais ramos juridicos, pode-se citar, a titulo exemplificativo, o poder normativo concedido à ANVISA pela Lei Federal n. 9.782, de 26 de janeiro de 1999, para através das resoluções da diretoria colegiada regulamentar matéria atinente ao Direito Sanitário. Essa normatização tem razão de existir na impossibilidade da matéria ser especificada em lei, dadas as transformações constantes na sociedade que inviabilizariam a adequação das normas as novas realidades sociais prejudicando o direito da população e o atendimento do preceito constitucional que designa a saúde como direito de todos e dever do Estado.

Outros principios e artigos inseridos na Constituição Federal determinam condutas atribuidas ao setor público ou a serem implementadas ou garantidas pelo mesmo, para que a vida, saúde, segurança sejam preservadas, entre eles o caput do art. $5^{\circ}$ ao garantir o direito à vida e à segurança, o inciso III do art. $1^{\circ}$ ao determinar a dignidade da pessoa humana como fundamento do Estado Democrático de Direito, o art. 6o definindo como direitos sociais à saúde e à segurança e o art. 196 afirmando que a saúde é direito de todos e dever do Estado.

A competência legislativa em Direito Sanitário é concorrente, ou seja, tanto a União quanto o Estado e o Distrito Federal podem editar leis em sentido estrito, conforme depreende-se do art. 24, XII da Constituição Federal. Entretanto, deve-se salientar que a redação do dispositivo constitucional não veda a competência concorrente também do Municipio, pois o art. 30, I e II da Carta Magna é expresso no sentido de conferir competência municipal para legislar sobre assuntos de interesse local e suplementar a legislação federal e estadual no que couber.

O Tribunal de Justiça de São Paulo(12) posicionou-se nesse sentido:

Mandado de segurança - Vedação municipal ao sistema self service, nos postos de abastecimento de combustiveis. Legalidade. Competência do Municipio de legislar, de forma suplementar, sobre saúde pública; regulamentando questões de interesse local. Artigos 23, II e 30, I, da Constituição da República. Afronta aos principios constitucionais da tripartição do exercício do poder e da legalidade; da livre iniciativa e da livre concorrência. Inocorrência. Recurso não provido. (grifos nossos)

(12) TJSP - AC n. 115.888-5 - 7 $7^{\mathrm{a}}$ CDPúb. - Rel. Des. Sérgio Pitombo - J. 12.2.2001 JCF.23 JCF.23.II JCF.30 JCF.30.I. 
A situação da ANVISA é legitima frente as explanações apresentadas, visto que a edição normativa é autorizada por lei que instituiu a entidade considerada pela doutrina como autarquia de regime especial (agência reguladora), uma vez que tem peculiaridades em relação às demais autarquias comuns. Dentre tais caracteristicas especiais pode-se citar a forma de investidura de seus dirigentes, sua maior autonomia frente à entidade que as criou, administradores com mandato específico, e o poder normativo atribuido por norma legal.

A Lei Federal n. 9.782, de 26 de janeiro de 1999, pode ser considerada a norma legal a que se refere o art. 197 da CF, no tocante à normatização sanitária, ao especificar que:

São de relevância pública as ações e serviços de saúde, cabendo ao Poder Público dispor, nos termos da lei, sobre sua regulamentação, fiscalização e controle, devendo sua execução ser feita diretamente ou através de terceiros e, também, por pessoa física ou jurídica de direito privado.

A Constituição Federal não relega à reserva legal ou melhor não exige a lei em sentido estrito para regular, fiscalizar e controlar os serviços de relevância pública, tendo em vista que cabe ao poder público dispor sobre esses temas, nos termos especificados na lei que, por sua vez, já foi editada, recebendo a denominação de Lei n. 9.782, de 26 de janeiro de 1999. Assim, basta lei autorizadora que defina os limites para o exercício da atividade normatizadora dessas matérias.

Alguns autores vêem diferenças no termo regulamentação e regulação, consideram que o primeiro englobaria matérias próprias de tratamento por intermédio de decreto do executivo, portanto de esclarecimento e facilitação da fiel execução da lei que visa aplicar, não podendo ser concebido sem a presença da norma legal que objetiva esclarecer, sendo vedado a criação de direitos e obrigações não previstos na lei.

O termo regulação seria mais amplo açambarcando tanto a regulamentação quanto a atividade legisferante.

O melhor posicionamento é no sentido de que o texto constitucional não estabeleceu diferenças na terminologia acima discutida, compreendendo os termos como sinônimos devendo ser entendidos dentro do contexto aplicado. Tais diferenciações foram feitas pela doutrina e não pelo legislador constituinte. Indo um pouco mais além, percebe-se que mesmo aceitando-se a diferenciação dos vocábulos esbarrar-se-ia no termo "controle" que, por si só, induz a atividade normativa, já que dificilmente aquele que tem a competência para controlar algo não o regula e regulamenta.

Os princípios como requisito identificador da autonomia de uma disciplina, são proposições básicas que estruturam, fundamentam e dão organicidade a um sistema ou subsistema jurídico. Existem principios de caráter geral voltados à fundamentação dos mais primitivos esboços de ordenamento jurídico e relacionados, invariavelmente, a expressões do 
jusnaturalismo como, por exemplo, o princípio de que ninguém poderá se beneficiar de sua própria torpeza, ou da vedação do enriquecimento ilícito. Estes ícones, se salutar utilizar dessa expressão, podem ser aplicados por todos os ramos autônomos do direito, sem perder o seu sentido original.

A doutrina ${ }^{(13)}$ apresenta uma conceituação precisa de principio, diferenciam os principios decorrentes do Direito Especial daqueles do comum e das normas de exceção, bem como delimitam a possibilidade da aplicação da analogia e da interpretação extensiva:

Os principios gerais de um sistema juridico e suas correspondentes regras tendentes a realizá-lo, normalmente, formam um todo, um conjunto orgânico, cujas partes se prendem umas às outras por seqüência lógica e estrutural.

Mas, em dadas circunstâncias, impõe-se a interrupção dessa seqüência e o destaque e desenvolvimento de alguma de suas partes, ou de particulares relações, para a consecução de um fim que os princípios e regras do direito comum, por sua generalidade, não poderiam alcançar.

Esse fim especial não consiste, unicamente, na satisfação de uma particular e restrita utilidade, porventura transformada em causa exclusiva do direito especial ou singular, porque a chamada exceção, que este direito caracteriza, tanto pode ampliar, quanto restringir as faculdades outorgadas pelos principios gerais.

Causas do direito especial, ao contrário, são as particulares necessidades ditadas pela justiça, ou por circunstância de ordem moral, ou social, ou pública, ou prática, quando não de eqüidade.

As normas de direito comum formam ramos do direito, como o direito civil, o direito público interno; as de direito especial formam outros ramos ou sub-ramos, como o direito comercial, o direito tributário, o direito do trabalho. As normas excepcionais, restritivas de direito, tanto podem referir-se ao direito comum, quanto ao direito especial.

Se de direito especial, as normas juridicas comportam tanto quanto as de direito comum, interpretação extensiva, ou analógica dentro da ratio legis que as determina, quando aquele direito forma um todo orgânico; se de exceção ou restritivas de direito, não podem ser aplicadas por extensão, ou analogia e nelas só incidem os casos expressamente e taxativamente indicados.

Reina, contudo, grande confusão nesta matéria e é comum, por parte dos autores, identificação do direito especial com as normas excepcionais, confusão que, em parte, resulta da impropriedade da expressão "direito singular".

(13) RÁO, Vicente. Op. cit., p. 208. 
Outros principios surgem em virtude de peculiaridades encontradas exclusivamente ou de maneira mais acentuada em determinados ramos jurídicos autônomos, podendo ser implementados apenas nesses setores específicos sem desvirtuar sua origem. Exemplos dos denominados princípios especiais de Direito são o da proteção do consumidor (Direito do Consumidor), in dúbio pro reo (Direito Penal), pacta sunt servanda (Direito Civil), anterioridade (Direito Tributário), somente para citar alguns.

A importância do estudo dos principios que podemos denominar de principiologia, está na sua triplice função, quais sejam a interpretação, a integração e a criação das normas jurídicas.

A interpretação de um dispositivo normativo deve ser consentâneo com o ramo do Direito em que está inserido, pois tem a finalidade de determinar o real sentido e alcance da norma a ser aclarada. Nesta situação utiliza-se dos princípios gerais ou específicos de Direito para alcançar por dedução a interpretação mais adequada ao caso concreto.

Carlos Maximiliano(14), em sua obra Hermenêutica e Aplicação do Direito, ressalta a importância da interpretação na Ciência do Direito:

A Ciência do Direito não é só elemento relativamente criador, apto a suprir lacunas dos textos; mas também um fator de coordenação e exegese; auxilia a eliminar contradições aparentes e atingir, através da letra rígida, ao ideal jurídico dos contemporâneos.

Para ser um bom hermeneuta, há mister conhecer bem o sistema jurídico vigente. A ciência antecede a jurisprudência; é a primeira a inspirar soluções para os casos duvidosos. Oferece ainda vantagem de ver do alto os fenômenos e por isso, mais concorre para os compreender e resolver de acordo com os objetivos superiores da sociedade.

O Direito é um todo orgânico; portanto não seria lícito apreciar-lhe uma parte isolada, com indiferença pelo acordo com as demais. Não há intérprete seguro sem uma cultura completa. O exegeta de normas isoladas será um leguleio; só o sistematizador merece o nome de jurisconsulto; e, para sistematizar, é indispensável ser capaz de abranger, de um relance, o complexo inteiro, ter a largueza de vistas do conhecedor perfeito de uma ciência e das outras disciplinas, propedêuticas e complementares.

A integração das normas jurídicas é corolário da presença de lacunas no ordenamento jurídico. A existência de situações não previstas pelas normas jurídicas não autoriza o não julgamento do caso pelo juiz que nunca se escusa de analisar o fato ante a inexistência de previsão em dispositivos legais especificos. Nessas hipóteses deve socorrer-se da ana-

(14) MAXIMILIANO, Carlos. Op. cit., p.159. 
logia, costumes e principios gerais de Direito, para decidir, pondo fim a eventual conflito social. Essa situação tem dispositivo legal expresso no art. $4^{\circ}$ da Lei de Introdução ao Código Civil.

O ordenamento jurídico, portanto, considerado como um todo não apresenta lacunas, visto que ele próprio prevê os mecanismo que solucionam possiveis omissões.

Os principios gerais de Direito acima indicados também englobam os especificos de cada ramo jurídico, visto que auxiliam na solução de casos não previstos pelo legislador, dentro de cada matéria especializada.

A produção de normas juridicas tem nos principios um ponto de apoio como se fosse uma bússola indicadora da atividade normativa, visto que violar a lei é menos ofensivo ao sistema do que violar um principio. Este último direciona a atividade do legislador que o extrai por indução do ordenamento jurídico.

Passadas as explicações preliminares, retorna-se ao foco da análise, a existência de princípios especificos do Direito Sanitário.

O primordial e mais amplo princípio do Direito Sanitário extraído por indução da legislação sanitária em vigor poderia ser denominado de principio da busca constante da preservação ou proteção da saúde, que seria o gênero do qual a promoção, prevenção e recuperação da saúde são espécies.

A jurisprudência(15) reconhece principios próprios do Direito Sanitário também denominado por alguns estudiosos Direito da Saúde:

Portaria n. 344/98 do Ministério da Saúde - Manipulação de Substâncias Retinóides - No conflito entre os principios da isonomia e da livre concorrência entre as farmácias de manipulação e a indústria farmacêutica e o princípio da prevenção e proteção da saúde, deve prevalecer este último, uma vez que a saúde é concebida como direito de todos e dever do Estado, sendo de relevância pública as ações e serviços a ela relativos. Apelação improvida. (grifos nossos)

Saúde pública - Proteção - Dever do estado - É dever do poder público, em qualquer de suas esferas (federal, estadual ou municipal) velar pela proteção da saúde dos seus cidadãos. E a necessidade de proteger-se a saúde e a vida, como exigência que emerge dos principios fundamentais em que repousa o próprio direito natural, se sobrepõe a qualquer outro interesse, ainda que se ache este tutelado pela lei. Precedentes jurisprudenciais. Agravo regimental improvido. Votação indiscrepante. (grifos nossos)

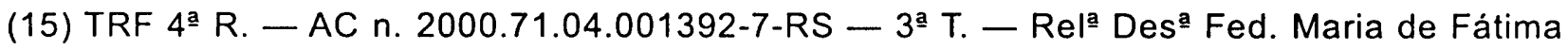
Freitas Labarrère - DJU 12.6.2002 - p. 341 e TJPE - AgRg 85648-4/01 - Rel. Des. Márcio Xavier - DJPE 6.11.2002. 
A preservação da saúde engloba as três espécies acima indicadas, tendo em vista que o verbo preservar significa em sentido amplo a utilização de todos os meios existentes e ao alcance para resguardar um bem juridicamente tutelado.

A promoção envolve a formulação e implantação de politicas sociais, econômicas e de saúde pelo governo, objetivando assegurar à população como um todo, meios de manter-se em niveis aceitáveis de existência digna. Nessa principiologia estariam inseridos a politica habitacional, de saneamento básico, o fome zero do governo Lula, uma reestruturação do Sistema Único de Saúde, bem como outros projetos que procurem implementar soluções conjunturais e estruturais atingindo um número indeterminado de pessoas.

A prevenção aproxima-se da promoção em alguns aspectos, visto que visa indices aceitáveis de dignidade humana, diferenciando-se dela no público alvo a ser atingido, uma vez que nesta o objetivo é a população no geral, enquanto naquela determinados grupos ou áreas de risco são determináveis. A atividade da vigilância sanitária e epidemiológica se inclui basicamente nesse contexto, pois o exercicio do poder de polícia da vigilância sanitária e a conduta preventiva epidemiológica e controle de zoonoses tem direcionamento específico, com campanhas e atividades programadas, direcionadas a um fim num primeiro momento restrito, porém com reflexos conjunturais amplos.

A recuperação da saúde engloba uma atividade circunscrita à reabilitação de pessoas enfermas ou debilitadas, visando seu restabelecimento e reinserção na vida social e econômica do país. A função primordial desse instituto não é só recuperar a saúde da população, mas também o restabelecimento mais rápido possivel para que os cidadãos economicamente ativos continuem produzindo para o desenvolvimento do país e evitando assim que os gastos com os serviços de saúde se mantenham em niveis elevados, onerando os cofres públicos.

Numa análise mais abrangente pode-se dizer que a promoção, prevenção e recuperação da saúde tem como objetivo final a implementação de um sistema interdependente que visa ao mesmo tempo manter a saúde da coletividade em niveis aceitáveis e reduzir os gastos públicos com as seqüelas de uma saúde individual precária que traz reflexos nos órgãos da previdência pública aumentando o ônus dos países no pagamento de aposentadorias por invalidez que se caracterizam pela precocidade e prejuizo à economia mundial.

Essa preocupação decorre do aumento da dívida pública associada ao pagamento de benefícios previdenciários em contrapartida à diminuição do recolhimento das contribuições que garantem o equilibrio atuarial do sistema de pecúlios, pois como visto acima a população economicamente ativa fica reduzida e, conseqüentemente, o sistema da Seguridade Social é afetado. 


\section{CONCLUSÃO}

Os prenúncios da autonomia do Direito Sanitário no discorrer do presente artigo restou devidamente caracterizado, ante a existência de principios, institutos e conceitos próprios e dos elementos a seguir enumerados.

A disciplina é ministrada em diversas universidades do país e do exterior.

O Poder Judiciário aplica seus preceitos e cada vez mais cresce o número de obras publicadas no mundo que tratam desse ramo juridico.

Diversos dispositivos normativos regulam as questões relacionadas à saúde, tendo, por exemplo, o Estado de São Paulo um Código Sanitário e outro de Saúde.

Constata-se o pleno desenvolvimento do Direito Sanitário, reflexo de um âmbito de atuação cada vez maior na busca constante do poder público no resguardo e preservação da saúde.

Mesmo para aqueles que compartilham da opinião do Direito Sanitário ser mera expressão do Direito Administrativo, inegável a existência de principios especificos condutores do administrador público na solução de questões sanitárias, além do vasto campo suscetivel e suficiente para autorizar uma análise detalhada e especial da matéria.

A vida humana resguardada por esta nova disciplina juridica, engloba o meio ambiente, os alimentos, o saneamento básico, a limpeza pública, a moradia, o atendimento médico, planos de saúde e tudo que direta ou indiretamente relacione-se com a saúde pública.

Infere-se a enorme amplitude e complexidade das questões relacionadas ao Direito Sanitário, ensejando uma análise mais detida a ponto de permitir seu estudo como ramo juridico autônomo. O pleno desenvolvimento e intenso relacionamento com os outros diversos ramos do Direito, tais como penal, administrativo, ambiental, constitucional, também é perceptivel e salutar na medida em que a autonomia de todos os ramos é relativa e não absoluta, já que somente o Direito, entendido como um todo, como ciência, é independente e absolutamente autônomo.

Extrai-se dos diversos elementos analisados no presente trabalho que o Direito Sanitário como disciplina jurídica está caminhando para o reconhecimento de sua autonomia, apenas esperando que os operadores do Direito se conscientizem desse fenômeno e busquem tratá-lo como ramo juridico, sem apego a preconceitos, baseando-se nos crescentes estudos catedráticos sobre a matéria e no amplo campo de atuação existente e a cada dia comprovado pela jurisprudência, além das atividades dos órgãos públicos detentores do poder de policia sanitária. 


\section{REFERÊNCIAS BIBLIOGRÁFICAS}

ANTUNES, Paulo de Bessa. Direito ambiental, $5^{\mathrm{a}}$ ed. Rio de Janeiro: Lumen Juris, 2001, p. 657.

CHIMENTI, Ricardo Cunha. Direito tributário, $4^{a}$ ed. São Paulo: Saraiva, 2002. vol. 16, p. 211.

DI PIETRO, Maria Sylvia Zanella. Direito administrativo, $8^{\mathrm{a}}$ ed. São Paulo: Atlas, 1997, p. 566.

DIAS, Helio Pereira. Direitos e obrigações em saúde, $1^{\text {a }}$ ed. Brasilia: ANVISA, 2002, p. 387.

. Flagrantes do ordenamento jurídico sanitário, $1^{\text {a }}$ ed. Brasília:

ANVISA, 2000, p. 178.

DINIZ, Maria Helena. Código Civil anotado, 6로 ed. São Paulo: Saraiva, 2000, p. 1286.

GONÇALVES, Carlos Roberto. Direito civil: parte geral, 4르 ed. São Paulo: Saraiva, 1999. vol. 1, p. 179.

1999. vol. 5, p. 150.

Direito das obrigações: parte geral, $3^{\text {a }}$ ed. São Paulo: Saraiva, Direito das obrigações: parte especial. São Paulo: Saraiva, 1999. vol. 6, p. 190.

GOUVEIA, Roberto. Saúde pública, Suprema Lei: a nova legislação para a conquista da saúde. São Paulo: Mandacaru, 2000, p. 223.

GUSMÃO, Paulo Dourado de. Introdução ao estudo do direito, $8^{\mathbf{a}}$ ed. Rio de Janeiro: Forense, 1978, p. 539.

Lei n. 10.294, de 20 de abril de 1999. Dispõe sobre Proteção e Defesa do Usuário do Serviço Público do Estado de São Paulo e dá outras providências.

Lei n. 8.078, de 11 de setembro de 1990. Dispõe sobre a Proteção do Consumidor e dá outras providências.

MACHADO NETO, A. L. Compêndio de introdução à ciência do direito. São Paulo: Saraiva, 1988, p. 281.

MACHADO, Hugo de Brito. Curso de direito tributário, 14를 ed. São Paulo: Malheiros Ed., 1998, p. 414.

MAXIMILIANO, Carlos. Hermenêutica e aplicação do direito, 19ª ed. Rio de Janeiro: Forense, 2002, p. 342.

MEDAUAR, Odete. Direito administrativo moderno, $5^{\mathbf{a}}$ ed. São Paulo: Ed. Revista dos Tribunais, 2001, p. 494.

MEIRELLES, Hely Lopes. Direito administrativo brasileiro, $22^{\mathrm{a}}$ ed. São Paulo: Malheiros Ed., 1997, p. 733. 
Direito municipal brasileiro, $13^{\mathrm{a}}$ ed. São Paulo: Malheiros Ed., 2003 , p. 882.

MILARÉ, Edis. Direito do ambiente, $2^{\mathrm{a}}$ ed. São Paulo: Ed. Revista dos Tribunais, 2001, p. 783.

MONTORO, André Franco. Introdução à ciência do direito, 24르 ed. São Paulo: Ed. Revista dos Tribunais, 1997, p. 620.

NADER, Paulo. Introdução ao estudo do direito, $1^{\text {a }}$ ed. Rio de Janeiro: Forense, 2000, p. 412.

PINHO, Rodrigo Cesar Rebello. Da Organização do Estado, dos Poderes e histórico das Constituições, 3ª ed. São Paulo: Saraiva, 2002, vol. 18, p. 164.

Teoria geral da constituição e direitos fundamentais, $3^{\mathbf{a}}$ ed. São Paulo: Saraiva, 2002, vol. 17, p. 198.

RÁO, Vicente. O direito e a vida dos direitos, 4aㅡ ed. São Paulo: Ed. Revista dos Tribunais, 1997, vol. 1, p. 519.

RIBEIRO, Mauricio Antonio. Coletânea de Legislação Administrativa. São Paulo: Ed. Revista dos Tribunais, 2001, p. 1177.

RODRIGUES, Silvio. Direito civil: dos contratos e das declarações unilaterais da vontade, 23a ed. São Paulo: Saraiva, 1995, vol. 3, p. 400.

. Direito civil: parte geral das obrigações, $23^{a}$ ed. São Paulo: Saraiva, 1995, vol. 2, p. 330.

vol. 1, p. 350.

Direito civil: parte geral, 25a ed. São Paulo: Saraiva, 1995,

ROSA, Marcio Fernando Elias. Direito administrativo, $3^{\text {a }}$ ed. São Paulo: Saraiva, 2002, vol. 19, p. 231.

TEMER, Michel. Elementos de direito constitucional, $18^{\mathrm{a}}$ ed. São Paulo: Malheiros Ed., 2002, p. 224.

WAMBIER, Luiz Rodrigues. Curso avançado de processo civil: processo cautelar e procedimentos especiais, 3a ed. São Paulo: Ed. Revista dos Tribunais, 2000, vol. 1, p. 762.

. Curso avançado de processo civil: processo de execução, 3ª ed. São Paulo: Ed. Revista dos Tribunais, 2000. vol. 2, p. 418.

Curso avançado de processo civil: teoria geral do processo e processo de conhecimento, $3^{a}$ ed. São Paulo: Ed. Revista dos Tribunais, 2000 , vol. 3 , p. 348 . 